\title{
Analysis of the Factors Affecting the Productivity of Fractured Horizontal Wells in Changji Low Mobility Tight Oil of Xinjiang Oilfield
}

Li-feng LIU*

PetroChina Research Institute of Petroleum Exploration \& Development

Beijing, China

liulifeng86@petrochina.com.cn

\section{Xin WANG}

Sinopec Research Institute of Petroleum Exploration\&

Production,

Beijing, China

\begin{abstract}
Tight oil is one of the important substitute areas of the oil industry in China. The effective development of tight oil is of great significance for the development of China's economic sustainable and stable. Changji tight oil of Xinjiang oilfield is a typical Chinese blocks of tight oil, it has the characteristics of high viscosity and low mobility. With reservoir numerical simulation method, based on the historical fitting of tight oil production data in Changji oilfield, Xinjiang, The author have calculated and analyzed the formation factors, engineering factors and fluid factors of the tight oil production. The results show that the SRV volume of the fracturing, the spacing of the fracturing section and the size of formation matrix created by network fracture are the main parameters that affect the initial productivity of tight oil. The SRV volume, the formation pressure coefficient and the viscosity of crude oil are the main parameters that affect the cumulative production.
\end{abstract}

Keywords- Changji tight oil, productivity, factor analysis, numerical simulation

\section{INTRODUCTION}

The Lucaogou group tight oil of Xinjiang Changji Oilfield in China is distributed in Jimusaer sag of the eastern Junggar Basin, the Exploration forecast reserves of Lucaogou group is more than 10 million tons ${ }^{[1-3]}$, And it has great development potential. But the conditions of Lucaogou Formation is very complex, and it has the characteristics of high viscosity and low fluidity compared with other tight oil, and because of the understanding of the factors that affect the production capacity of oil well is not clear, the development of tight oil is not ideal ${ }^{[4]}$. Through the method of reservoir numerical simulation, the author analyzed the factors that affect the productivity of staged fracturing horizontal wells of tight oil reservoir in Changji, Xinjiang, and found the main control factors. This study provide a technical support for the effective development of tight oil in Changji, Xinjiang.

\author{
Qi-quan RAN \\ PetroChina Research Institute of Petroleum Exploration \& \\ Development \\ Beijing, China
}

\section{SimUlation PARAMETER FITTING}

The J3 well of Changji oil field in Xinjiang is selected as the research object, and using CMG reservoir numerical simulation software to carry on the fitting of Geology and engineering parameters, and provide the basic parameters for the analysis of the influence factors of productivity. The production curve of $\mathrm{J} 3$ well is shown in Figure 1, and the bottom-hole pressure is used to fit the daily production of fractured horizontal wells. The fitting results are shown in Figure 2.

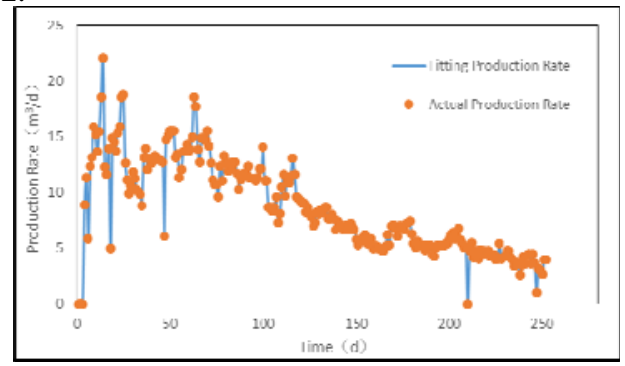

Fig.1 The production curve of J3 well

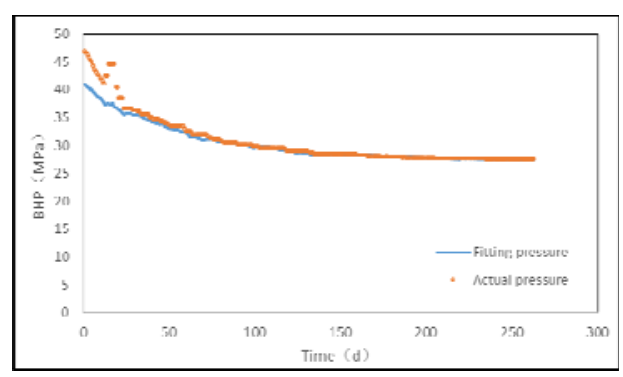

Fig.2 Fitting results of bottom-hole pressure

It can be found From Figure 2 that the actual bottom hole pressure of $\mathrm{J} 3$ well is slightly higher than the fitting line in the early stage of the production. This is because the hydraulic fracturing will cause a pressure increase in the formation near wellbore in an actual production process, and 
it will not affect the fitting effect in the calculation. The actual bottom-hole pressure and the fitting curve of the middle and late stage of production are basically coincident, and this indicated a good fitting. The geological parameters and fracture parameters of the $\mathrm{J} 3$ well are obtained as shown in table 1.

TABLE I. GEOLOGICAL PARAMETERS AND FRACTURE PARAMETERS OBTAINED BY FITTING

\begin{tabular}{|l|l|l|l|}
\hline \multicolumn{2}{|c|}{ Geological Parameters } & \multicolumn{2}{l|}{ Artificial Fracture Parameters } \\
\hline Parameters & $\begin{array}{l}\text { Fitted } \\
\text { values }\end{array}$ & Parameters & $\begin{array}{l}\text { Fitted } \\
\text { values }\end{array}$ \\
\hline Reservoir Thickness (m) & 10 & Number of Fractures & 17 \\
\hline Permeability(mD) & 0.01 & $\begin{array}{l}\text { Effective Fracture } \\
\text { Half-length(m) }\end{array}$ & 80 \\
\hline Porosity(\%) & 9 & Fracture spacing & 70 \\
\cline { 1 - 2 } Original Oil Saturation(f) & 0.67 & Fracture conductivity & 17.5 \\
\hline Crude Oil Density (kg/m3) & 0.888 & (D.cm) & \\
\hline Viscosity (cp) & 9.5 & 15 &
\end{tabular}

III. ANALYSIS OF INFLUENCING FACTORS OF PRODUCTION CAPACITY

\section{A. The Influence of Reservoir Parameters on Productivity}

\section{1) The effect of permeability on productivity}

The simulation is carried out by using the geological parameters and fracture parameters obtained in the fitting. According to the permeability distribution of Xinjiang tight oil, the reservoir matrix permeability of $0.2 \mathrm{mD}, 0.05 \mathrm{mD}$, $0.1 \mathrm{mD}, 0.15 \mathrm{mD}$ and $0.01 \mathrm{mD}$ were respectively calculated by the model, and the calculation results are shown in Figure 3. According to the simulation results, the initial production and cumulative production of fractured horizontal wells are plotted with the change of permeability, as shown in Figure 4.

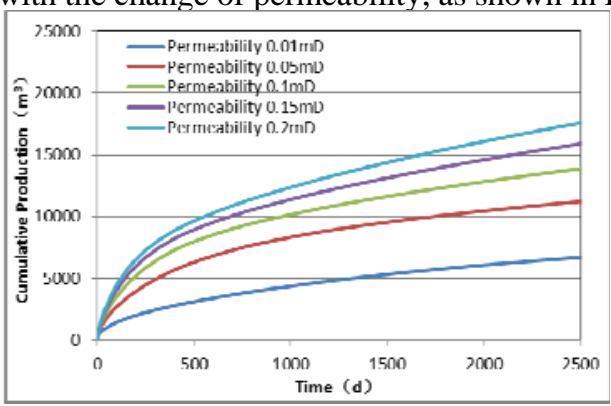

Fig. 3 Effect of matrix permeability on the production of horizontal well

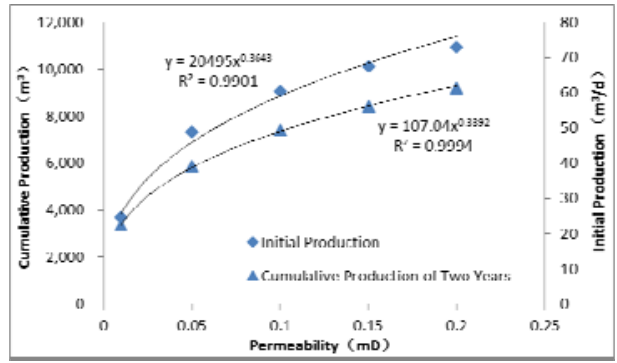

Fig. 4 Correlation between permeability and production

With the increase of permeability, the initial production and cumulative production increase rate is slower gradually. The initial production and cumulative production of fractured horizontal wells and permeability exhibits an approximate logarithmic correlation.

2) The effect of porosity on productivity

The physical property of tight oil reservoir is poor, and it has the characteristics of typical low porosity and low permeability. The porosity of tight oil reservoir in Changji, Xinjiang is usually less than $9 \%$, and the porosity of $1 \%, 3 \%$, $6 \%$ and $9 \%$ were respectively calculated by the model. The calculated results are shown in Figure 5. According to the simulation results, the initial production and cumulative production of fractured horizontal wells are plotted with the change of porosity, as shown in Figure 4.

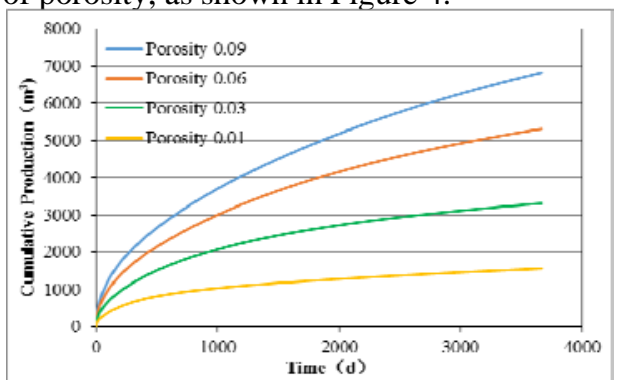

Fig. 5 the effect of porosity on the production of horizontal well

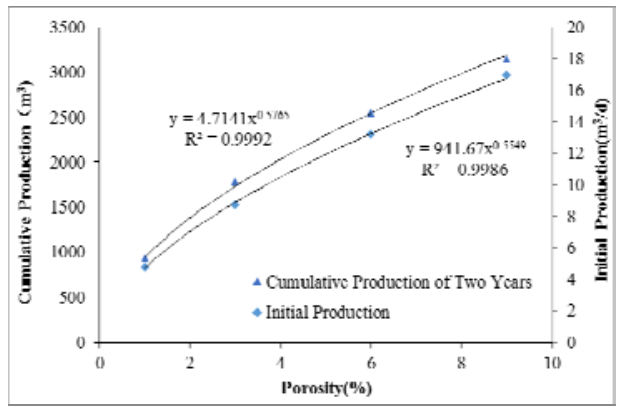

Fig. 6 correlation between porosity and production

The physical property of the reservoir is of vital importance to the oil well productivity. The better the physical property of the reservoir, the higher the production capacity of the oil well. But with the increase of permeability, the initial production and cumulative production increase rate is slower gradually. The initial production and cumulative production of fractured horizontal wells and 
permeability exhibits an approximate power function correlation.

\section{B. The Effect of Fracturing Parameters on Productivity}

1) The effect of the fracture spacing on productivity

Under the condition of the same horizontal well length, the shorter the distance between the fractured segments, the more the number of artificial fractures. This will increase the contact area of the fracture and reservoir matrix, which can improve the productivity of fractured horizontal wells. Select the $70 \mathrm{~m}, 50 \mathrm{~m}, 30 \mathrm{~m}$ and $20 \mathrm{~m}$ of the length of interval for simulation, which correspond to 17, 23, 39 and 59 of the number of artificial cracks, and the results shown in figure 7. According to the simulation results, the initial production and cumulative production of fractured horizontal wells are plotted with the change of fracture spacing, as shown in Figure 8.

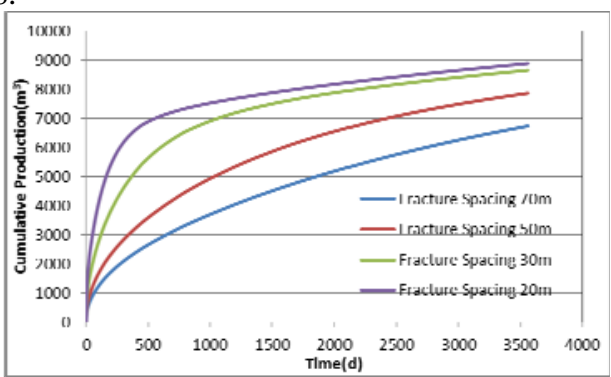

Fig. 7 Effect of section spacing on production of horizontal well

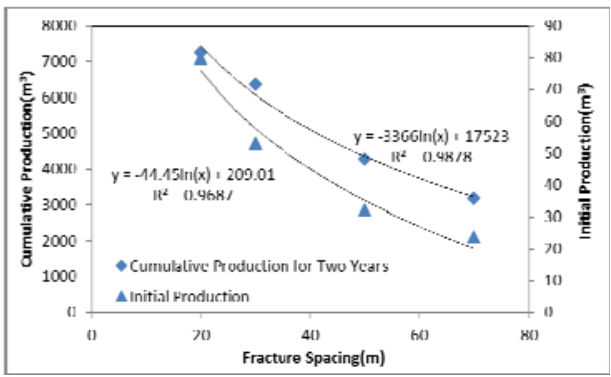

Fig. 8 Correlation between section spacing and production

With the decrease of the interval, the increasing rate of initial and cumulative production becomes more and more slowly, and the initial production and cumulative production of fractured horizontal wells and fracture spacing exhibits an approximate logarithmic correlation. From the point of view of the long term production of fractured horizontal wells, when the distance between the segments is reduced to $30 \mathrm{~m}$, the effect of short segment spacing on the production capacity is very small.

2) The effect of the fracture length on productivity

The longer the length of hydraulic fractures, the greater the contact area of the fracture and the reservoir matrix, and the better the development of the oil well. Select the $80 \mathrm{~m}, 100 \mathrm{~m}, 120 \mathrm{~m}, 150 \mathrm{~m}$ and $200 \mathrm{~m}$ of the length of fracture length for simulation, and the calculated results are shown in Figure 9 and figure 10.

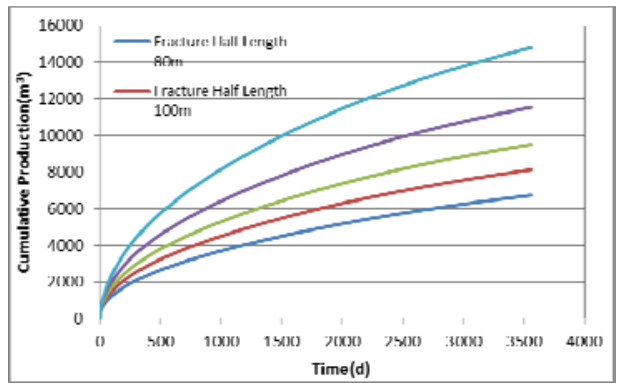

Fig. 9 The influence of the fracture length on the production of horizontal well

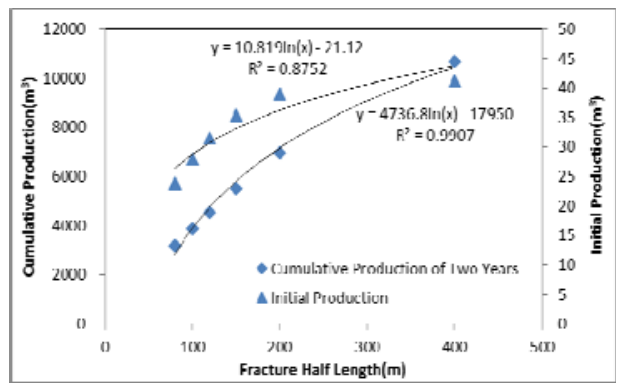

Fig. 10 Correlation between fracture length and production

Along with the increase of the crack half length, the initial production rate increases slowly, but the cumulative production continues to increase. The initial production of fractured horizontal wells and fracture length exhibits an approximate logarithmic correlation. But as the development time is prolonged, the length of the crack and the cumulative yield are more and more close to the linear relationship.

3) The effect of the fracture conductivity on productivity

The greater the conductivity of the hydraulic fracture, the smaller the resistance of fluid flow in the fracture, and the higher the production of the fractured horizontal well. Select the 0.5D.cm, 2.5D.cm, 5D.cm and 10D.cm of the numerical value of the artificial fracture conductivity for simulation, and the calculated results are shown in Figure 11 and figure 12 .

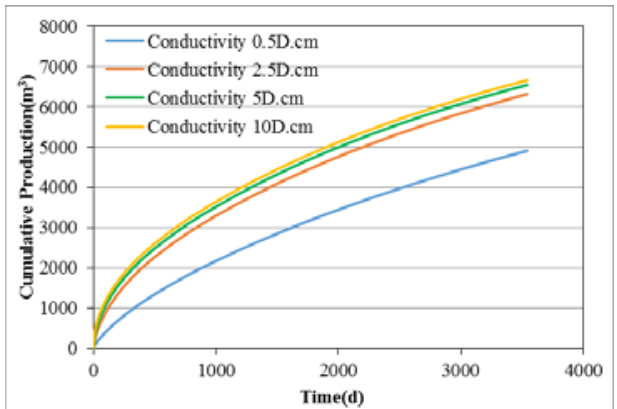

Fig. 11 Effect of conductivity on the production of horizontal well 


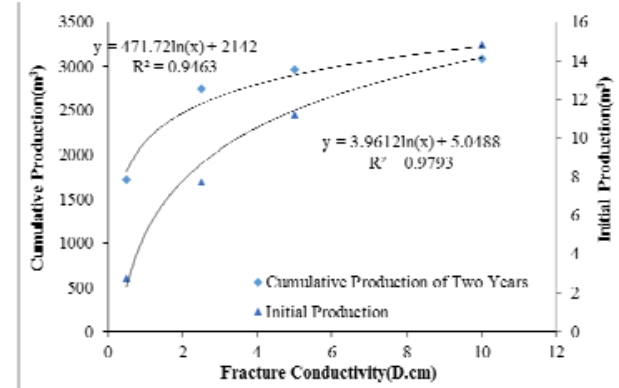

Fig. 12 The correlation between fracture flow conductivity and production

With the increase of fracture conductivity, the increasing ratio of initial and cumulative production becomes more and more slowly. The production of fractured horizontal wells and fracture conductivity exhibit an approximate logarithmic correlation. From Figure 12, we can see that when the conductivity is greater than the $8 \mathrm{D} . \mathrm{cm}$, add conductivity has very little impact on the productivity of horizontal wells.

4) The effect of the size of the matrix rock mass formed by fracturing on productivity

Because of poor reservoir physical properties of tight oil, crude oil can be driven by a very limited distance. Therefore, in the development of tight oil,engineers usually take the method of volume stimulation which can "break" the reservoir into different sizes of matrix rock ${ }^{[5]}$. The size of matrix rock block is different, and the development of oil well has a certain difference.

Under the condition of not changing other engineering parameters of fractured horizontal wells of Changji tight oil, the simulation calculation of the development effect is made on the assumption that the fracturing forms matrix rock with the size of $10 \times 10 \mathrm{~m}, 14 \times 20 \mathrm{~m}, 35 \times 40 \mathrm{~m}$ and $70 \times 80 \mathrm{~m}$. The results are shown in Figure 13 and 14.

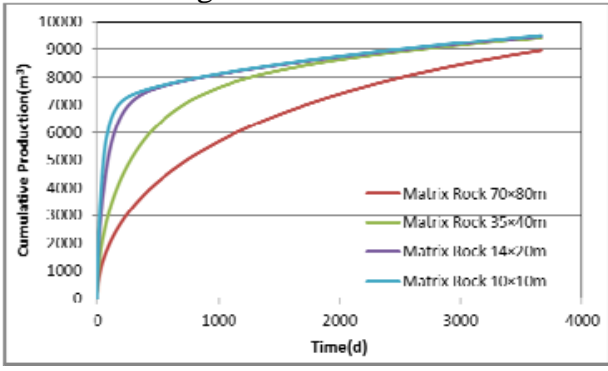

Fig. 13 The influence of the size of matrix rock on the production of horizontal well

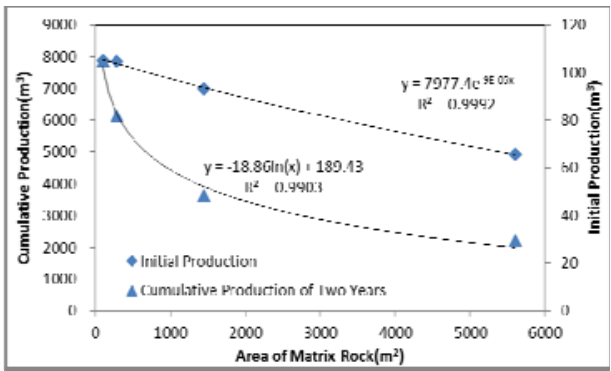

Fig.14 The correlation between the size of the matrix rock and production
The sizes of $10 * 10 \mathrm{~m}, 14 * 20 \mathrm{~m}, 35 * 40 \mathrm{~m}$ and $70 *$ $80 \mathrm{~m}$ matrix rock blocks correspond with the $100 \mathrm{~m}^{2}, 280 \mathrm{~m}^{2}$, $1440 \mathrm{~m}^{2}$ and $5600 \mathrm{~m}^{2}$ rock mass. It can be found from the figure that, with the reduction of the area of rock block, the initial production increased significantly, and the trend of the increase is similar to logarithmic growth, but the increase of cumulative production is not obvious. And the longer the development time, the smaller the effect of increasing production.

5) The effect of the SRV volume on productivity

The SRV volume of the hydraulic fracturing is one of these most important parameters in the volume stimulation of tight oil ${ }^{[6]}$. The bigger the SRV volume of the fracturing, the greater the control area of the horizontal well, and the better the reservoir development effect. Select 1.456 million cubic meters, 1.792 million cubic meters, 3.528 million cubic meters and 6. 272 million cubic meters of volume of SRV for simulation, and the results are shown in Figure 15 and 16.

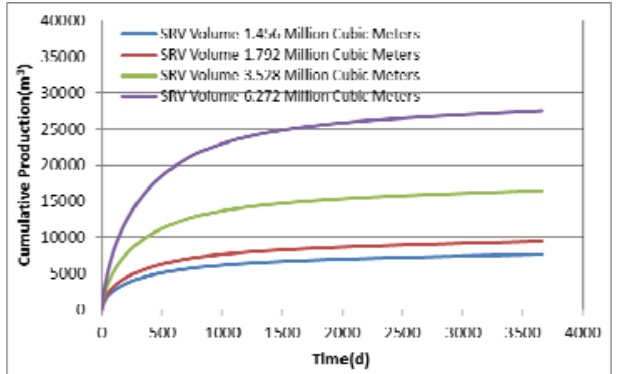

Fig. 15 Effect of SRV volume on the production of horizontal well

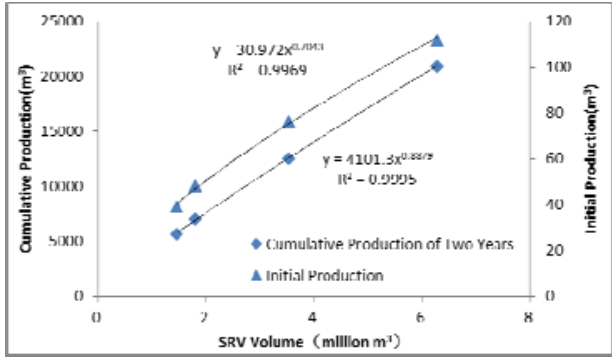

Fig.16 The correlation between SRV volume and production

With the increase of SRV volume, the initial and cumulative production of the fractured well increased linearly. By increasing the scale of fracturing, forming a larger volume of SRV, it is helpful to improve the development effect of fractured horizontal wells.

\section{The Effect of Fluid Parameters on Productivity}

1) The effect of viscosity of crude oil on productivity

Compared with the tight oil in other areas of China, one of the typical characteristics of Changji is that the viscosity of crude oil is large, and the flow property is poor ${ }^{[7-8]}$. The viscosity of crude oil in Changii is $9.5 \mathrm{mPa} \cdot \mathrm{s}$.According to the characteristics of tight oil in Changji, the viscosity of $9.5 \mathrm{mPa} \cdot \mathrm{s} 1.1 \mathrm{mPa} \cdot \mathrm{s}, 0.7 \mathrm{mPa} \cdot \mathrm{s}$ and $0.4 \mathrm{mPa} \cdot \mathrm{s}$ were selected for simulation to observe the effects of reduce the crude oil 
viscosity on well productivity. The results are shown in Figure 17 and 18.

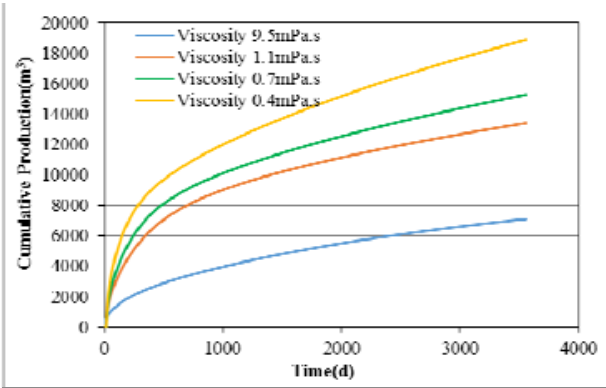

Fig. 17 The influence of the viscosity of crude oil on the production of horizontal well

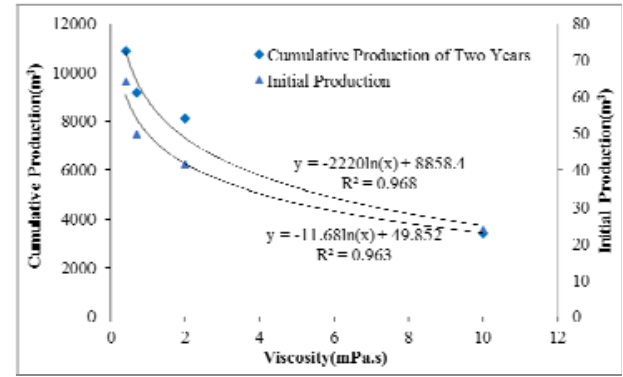

Fig. 18 Correlation between crude oil viscosity and production

With the decrease of the viscosity of crude oil, the increasing rate of initial and cumulative production becomes faster. The production of fractured horizontal wells and the viscosity of crude oil exhibit an approximate logarithmic correlation.

2) The effect of dissolved gas/oil ratio on productivity

The higher the gas/oil ratio (GOR), the more dissolved gas in the oil. In the oil well development, the dissolved gas in the crude oil will provide the driving force for the flow of crude oil, and increase the production of crude oil. According to the fluid characteristics of Changji tight oil, select the 20,50,100,150 and 200 of the GOR for simulation, observe the effects of different GOR of the crude oil on well productivity. The results are shown in Figure 19 and 20.

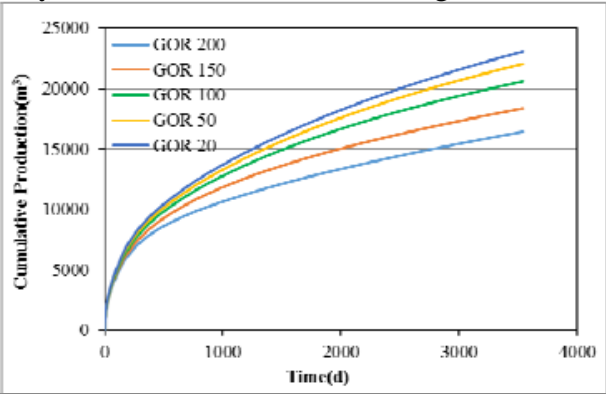

Fig. 19 Effect of gas oil ratio on the yield of horizontal wells

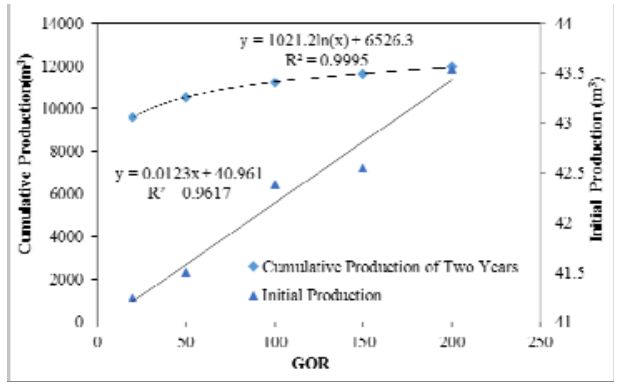

Fig. 20 Correlation between gas oil ratio and production

It can be seen in the figure that, with the increase of the ratio of oil to gas, the initial production and GOR of the crude oil showed a linear increase, and the cumulative production and GOR were similar to the logarithmic growth.

3) The effect of formation pressure coefficient on productivity

In tight reservoir, the flow of crude oil has obvious low velocity nonlinear flow characteristics. And the flow of crude oil into the wellbore needs to overcome the starting pressure gradient. That is to say, only when the pressure is greater than a certain value, the fluid begins to flow. The higher the formation pressure coefficient, the greater the pressure of the original formation, and the more the effective flow distance of fluid. In this case, the production of fractured horizontal wells is also greater. Select the 0.5, 0.8, 1, 1.2, 1.8 and 2 of the formation pressure coefficient for simulation. The results are shown in Figure 21 and 22.

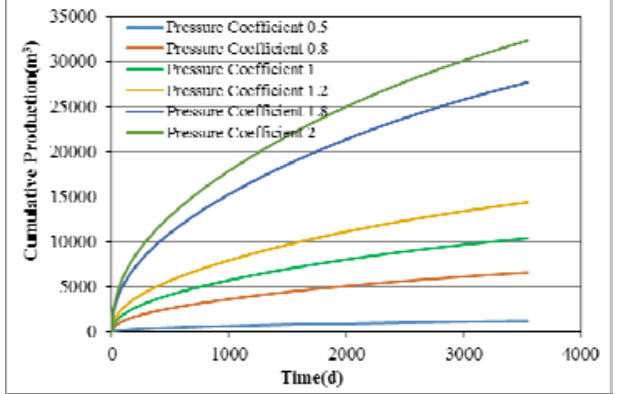

Fig. 21 The influence of pressure coefficient on the production of horizontal well

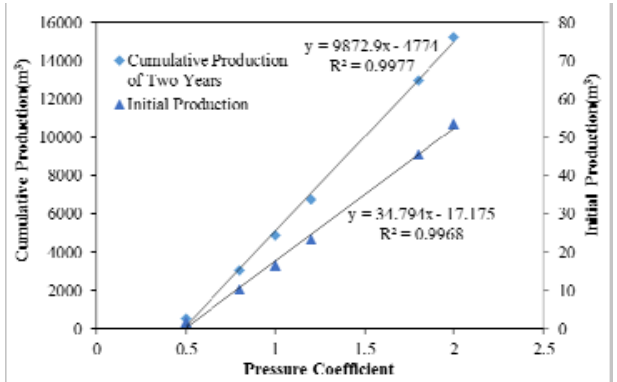

Fig. 22 Correlation between pressure coefficient and production

From the graph, we can find that with the increase of formation pressure coefficient, the initial and the cumulative production increase linearly. 


\section{Ranking of Productivity Influencing Factors}

Tight oil production capacity is affected by many factors, and the analysis of these factors was very difficult. In order to quantify the sensitivity of different influencing factors to the productivity of fractured horizontal wells, the influence factor $A_{i}$ of different factors on the productivity of the fractured horizontal wells are defined as follows:

$$
A_{i}=\frac{\Delta E_{i}}{\Delta E_{\max }}
$$

In the formula, $\Delta E_{i}$ is the change of production caused by the change of the parameters in each influence factor. $\Delta E_{\max }$ is the maximum value of production corresponding to the change of all the parameters. It can be found that the influence factor of the parameter which has the greatest influence is 1 . As long as the selected parameters change in a reasonable range, you can use $A_{i}$ to carry out the ranking of productivity influencing factors

The correlation of the factors affecting the production of tight oil production is sorted by the formula $4-1$, and the results are shown in Figure 23 and 24. Through the histogram of the multi factor, quantifying sensitivity of different influencing factors of tight oil to fracturing horizontal well initial production and cumulative production.

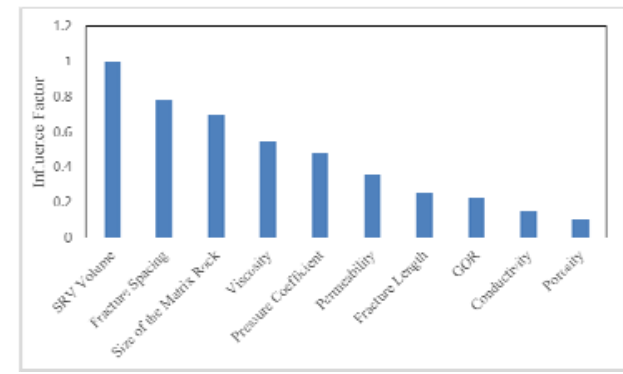

Fig. 23 Ranking of factors affecting initial production of tight oil

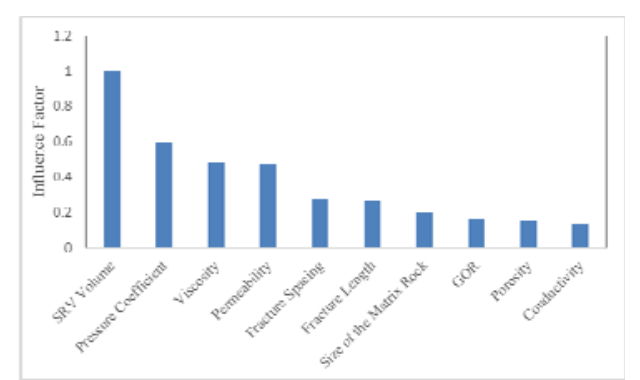

Fig.24 Ranking of factors affecting cumulative production of tight oil

It can be found from the histogram of multi factor that, the SRV volume of fracturing, fracturing spacing and the size of the matrix rock mass formed by fracturing are the key parameters that affect the production capacity of tight oil early. SRV volume, formation pressure and viscosity of crude oil is the main parameters of influencing factors on cumulative production of Changji tight oil.

\section{CONCLUSIONS}

This paper carried out an analysis of the influence factors of productivity based on geologic and engineering parameters of Changji tight oil in Xinjiang Oilfield. The main conclusions are as follows:

- There are many influence factors of productivity of fractured horizontal wells in Changji tight oil, and they can be divided into geological factors, engineering factors and the impact of fluid parameters on the production capacity.

- $\quad$ The SRV volume of fracturing, fracturing spacing and the size of the matrix rock mass formed by fracturing are the main parameters that affect the production capacity of tight oil in the early stage, and developers can improve the initial production of horizontal wells and quickly recover their cost by increasing the fracturing scale and reducing fracture spacing.

- $\quad$ SRV volume, formation pressure and viscosity of crude oil is the main parameters of influencing factors on cumulative production of Changji tight oil. And developers can consider increasing the scale of the fracturing operation and reducing the viscosity of crude oil to improve the EUR of their horizontal wells.

\section{ACKNOWLEDGMENT}

Supported by the National High-tech R\&D Program of China (863 Program) (Grant No. 2013AA064902).

\section{REFERENCES}

[1] Qiu Zhen, Li Jianzhong, Wu Xiaozhi, et al. Exploration status, main geologic characteristics and their differences of tight oil between America and China[J]. Lithologic Reservoirs, 2015,27(4):119-126.

[2] Kuang Lichun,Tang Yong,Lei Dewen,et al. Formation conditions and exploration potential of tight oil in the Permian saline lacustrine dolomitic rock,Junggar Basin,NW China [J]. Petroleum Exploration and Development,2012,39(6):657 667.

[3] Pang Zhenglian,Zou Caineng,Tao Shizhen,et al. Formation distribution and resource evaluation of tight oil in China [J]. China Engineering Science,2012,14(7):60 67.

[4] WU Chengmei, GUO Zhineng, TANG Fuping, et al. Early Exploitation Characteristics of Lucaogou Tight Oil of Permian in Jimusaer Sag, Junggar Basin[J]. XINJIANG PETROLEUM GEOLOGY, 2014,35(5):570 573.

[5] GUO Peng, YAO Lei-hua1,REN De-sheng. Fracture Distribution and Propagation Laws and Effect Analysis of Volume Fracturing in the Su 53 Block, Ordos Basin[J], Science Technology and Engineering, 2015,24(15):46-51.

[6] Meyer, B.R., and Bazan, L.W., 2011, A Discrete Fracture Network Model for Hydraulically Induced Fractures: Theory, Parametric, and Case Studies, Paper SPE 140514, presented at the SPE Hydraulic Fracturing Technology Conference, The Woodlands, Texas, USA, 2426 January.

[7] [Li Hongnan, Mao Xinjun, Hu Guangwen, et al. Characteristics and Productivity Prediction of Tight Reservoirs in Lucaogou Formation of Jimusaer Sag in Junggar Basin[J], Journal of oil and Gas Technology, 2014,36(10):40-44.

[8] Jia Chengzao, Zou Caineng, Li Jianzhong, et al. Assessment criteia, main types, basic features and resource prospects of the tight oil in China[J]. Acta Petrolei Sinica, 2012, 33(3): 343-350. 
[9] Sun Zandong, Jia Chengzao, Li Xiangfang,et al. Unconvertional oil \& gas exploration and development[M]. Beijing:Petroleum Industry

Press, 2011:1-150 